\title{
Systemisk behandling av akne
}

\author{
Systemisk behandling, oftest med tetrasykliner, gjerne i kombinasjon \\ med lokalbehandling, er nødvendig ved moderat til alvorlig akne. \\ Ved manglende effekt, særlig ved alvorlig og arrdannende sykdom, \\ bør pasienten henvises til hudlege for vurdering av systemisk \\ behandling med isotretinoin.
}

Se også kunnskapsprøve på www.tidsskriftet.no/quiz

\author{
Sonali Rathour Hansen \\ rasoao@sus.no \\ Carsten Sauer Mikkelsen \\ Susanne Kroon \\ Hudavdelingen \\ Stavanger universitetssjukehus \\ Postboks 8100 \\ 4068 Stavanger
}

Acne vulgaris er en sykdom i talgkjertlene som skyldes mikroorganismen Propionibacterium acnes, talgkjertelhyperplasi og overproduksjon av talg (1). Den rammer $80-85 \%$ av alle tenåringer og forsvinner som regel før 25 års alder. De mest alvorlige tilfellene ses hos gutter i alderen 17-19 år. Det er sammenheng mellom alvorlighetsgraden av akne og dårlig selvbilde, angst og depresjon, som igjen kan føre til fravær fra skole og arbeidsplass. Vellykket behandling gir markant forbedret psykisk helse (2).

I denne artikkelen omtales behandling av moderat til alvorlig acne vulgaris med særlig vekt på systemiske legemidler.

\section{Materiale og metode}

Grunnlaget for artikkelen er et ikke-systematisk litteratursøk i PubMed. Det ble gjort et skjønnsmessig utvalg av artikler ut fra forfatternes erfaring innen feltet.

\section{Kliniske funn}

Moderat akne kjennetegnes av mange inflammatoriske pustler. Ved mer alvorlig sykdom har pasientene dype pustler, noduli, pseudocyster og cyster.

Acne conglobata er kjennetegnet av nodulocystisk akne med kommuniserende cyster og tyktflytende puss. Smertefulle abscesser og uttalt arrdanning kan utvikles. Ved acne fulminans utvikler pasientene ulcerasjoner og nekrotisk akne med feber, nedsatt allmenntilstand, leddsmerter og leukocytose.

\section{Behandlingsprinsipper}

Kombinasjonsbehandling, der man angriper flere punkter i patogenesen, er viktig for et vellykket resultat. Moderat og alvorlig akne behandles med systemiske antibiotika, for eksempel tetrasykliner, gjerne i kombinasjon med lokale keratolytiske/antibakterielle midler, slik som adapalen, benzoylperoksid, klindamycin eller azelainsyre (tab 1). Pasienter som ikke responderer på igangsatt behandling og/eller utvikler arr eller har psykososiale belastninger på grunn av akne, bør vurderes med tanke på systemisk behandling med isotretinoin $(3,4)$.

Ved acne conglobata kan det være aktuelt med intralesjonal kortisonbehandling av utvalgte lesjoner. Ved acne fulminans er systemisk behandling med kortison nødvendig. Lokale retinoider, for eksempel adapalen, kan brukes som vedlikeholdsterapi for å hindre oppblussing etter avsluttet systemisk behandling (5).

\section{Antibiotika}

Tetrasyklinene inhiberer bakteriell proteinsyntese ved å inkorporeres i talgkjertelsekret, de inhiberer bakterielle lipaser og hindrer nedbrytning av lipider til fettsyrer som trigger inflammasjon (fig 1). Ifølge nyere retningslinjer er systemisk antibiotikabehandling kombinert med lokalbehandling førstevalget ved moderat og alvorlig akne.

Førstegenerasjonstetrasykliner, som tetrasyklin $\mathrm{HCl}$ og oksytetrasyklin, doseres $1 \mathrm{~g}$ daglig fordelt på to doser. Annengenerasjonstetrasykliner, som lymesyklin $300 \mathrm{mg}$, doksysyklin og minosyklin $100 \mathrm{mg}$, doseres kun én gang daglig. Minosyklin er ikke registrert $\mathrm{i}$ Norge. Ved mer uttalt og utbredt moderat akne der lavdose tetrasyklin ikke har gitt tilstrekkelig effekt, må midlet gis i en høyere dose.

Annengenerasjonstetrasykliner har bedre farmakokinetisk profil, og absorpsjonen påvirkes ikke av inntak av mat og melk. Det anbefales en maksimal behandlingstid på 3-4 måneder $(5,6)$, da effekten når et platå etter tre måneder. Tetrasyklin bør kombineres med lokalbehandling med retinoider og/eller benzoylperoksid, men ikke med klindamycinoppløsning, da dette gir liten tilleggsgevinst og høyere risiko for resistensutvikling. Det er ingen klinisk relevant interaksjon mellom p-piller og tetrasykliner. Tetrasyklin skal ikke anvendes samtidig med systemisk isotretinoin pga. risiko for intrakranial trykkstigning.

Erytromycin $500 \mathrm{mg}$ to ganger daglig kan forsøkes som alternativ til tetrasyklin, selv om det er beskrevet økende resistens mot $\mathrm{P}$ acnes. Trimetoprim med eller uten sulfametoksazol er ikke indisert ved acne vulgaris, blant annet pga. faren for alvorlige allergiske reaksjoner (6).

\section{Isotretinoin}

Isotretinoin, et vitamin A-syrederivat, er effektiv ved nodulær, cystisk og konglobat akne. Isotretinoin nedsetter talgproduksjonen og virker keratolytisk og antiinflammatorisk (fig 1). Behandling bør bare startes av spesialist $\mathrm{i}$ hudsykdommer eller av lege som har god kjennskap til forskrivningsreglene. Indikasjonen er alvorlig akne som ikke responderer på systemiske antibiotika, i kombinasjon med lokale midler. Ved nodulocystisk, arrdannende og trunkal akne og hos pasienter med store psykososiale belastninger pga. sykdommen bør man vurdere slik behandling tidlig (4). Vanlig dosering er 0,5-1 $\mathrm{mg} / \mathrm{kg} /$ dag daglig i fire måneder, ev. lenger. Kumulativ dose på $120-150 \mathrm{mg} / \mathrm{kg} / \mathrm{kur}$ reduserer faren for residiv. Effekten av isotretinoin skal evalueres først flere måneder etter avsluttet behandling, ettersom bedringen gjerne fortsetter i tiden etter. Tablettene tas sammen med mat, fordi dette gir best absorpsjon.

Vanligste bivirkninger av systemisk isotretinoin er tørre slimhinner, neseblødninger og tørr hud. Psykiske symptomer som depresjon og humørsvingninger er rapportert, men det er usikkert om dette skyldes midlet

\section{Hovedbudskap}

- Moderat og alvorlig akne skal behandles med systemisk tetrasyklin i kombinasjon med lokale midler, slik som adapalen og benzoylperoksid

- Pasienter med alvorlig og arrdannende akne som ikke responderer på systemiske antibiotikabehandling, skal behandles med isotretinoin 
Tabell 1 Behandlingsalternativer ved moderat til alvorlig akne

\begin{tabular}{|c|c|c|}
\hline & Papulopustuløst utslett & Noduløse lesjoner. Acne conglobata \\
\hline Første behandlingsvalg & $\begin{array}{l}\text { Systemisk antibiotika kombinert med lokal retinoid- } \\
\text { behandling, eventuelt med benzoylperoksid eller } \\
\text { azelainsyre i tillegg }\end{array}$ & $\begin{array}{l}\text { Høydose systemisk antibiotikum, kombinert med lokal } \\
\text { retinoidbehandling og/eller benzoylperoksid }\end{array}$ \\
\hline Annet behandlingsvalg & Systemisk isotretinoin & $\begin{array}{l}\text { Systemisk isotretinoin. Ved acne fulminanns også predni- } \\
\text { solon }\end{array}$ \\
\hline Alternativ for kvinner & $\begin{array}{l}\text { Systemiske antiandrogener, kombinert med lokal } \\
\text { behandling med retinoid, azelainsyre og/eller benzoyl- } \\
\text { peroksid }\end{array}$ & $\begin{array}{l}\text { Systemiske antiandrogener, kombinert med lokalbehand- } \\
\text { ling med retinoid, klindamycin og/eller benzoylperoksid }\end{array}$ \\
\hline Vedlikeholdsbehandling & $\begin{array}{l}\text { Lokalbehandling med retinoid, ev. kombinert med ben- } \\
\text { zoylperoksid }\end{array}$ & $\begin{array}{l}\text { Lokalbehandling med retinoid, ev. kombinert med ben- } \\
\text { zoylperoksid }\end{array}$ \\
\hline
\end{tabular}

eller hudsykdommen (7). Flere pasienter forteller om økt psykisk velbefinnende etter avsluttet behandling. Isotretinoin er teratogent, så sikker antikonsepsjon under hele behandlingen og i minimum fire uker etter seponering er obligatorisk.

\section{Antiandrogen behandling}

P-piller med cyproteronacetatetinyløstradiol og drospirenonetinylestradiol har antiandrogene egenskaper, virker hemmende på talgproduksjonen og kan brukes mot akne hos kvinner (fig 1).

Spironolakton er tidligere beskrevet som effektiv behandling i doser på $25-100 \mathrm{mg}$ to ganger daglig i minimum seks måneder. I en ny Cochrane-oversikt var det imidlertid liten effekt av spironolakton i behandling av akne (5). Antiandrogen behandling er kontraindisert hos menn.

\section{Annen behandling}

I studier der man sammenlikner laserbehandling, lysbehandling og fotodynamisk behandling (PDT) av akne, er det vist best effekt av fotodynamisk behandling ved inflammatorisk akne $(5,9)$. Dette gir redusert talgproduksjon og hemmer veksten av $\mathrm{P}$ acne. Behandlingen gir smerter. Optimalt behandlingsoppsett er ennå ikke avklart. Det er ikke grunnlag for å anbefale disse metodene foreløpig.

\section{Behandling av gravide}

Systemisk behandling med isotretinoin, p-piller og tetrasykliner er kontraindisert under hele graviditeten. Fra annet til tredje trimester kan systemisk behandling med erytromycin anvendes.

\section{Aknearr}

Aknearr kan være hypertrofiske eller hypotrofiske. Variasjon i inflammatorisk respons og genetisk predisposisjon ser ut til å avgjøre utviklingen (10). Hypertrofiske arr kan behandles med intralesjonelle kortikosteroidinjeksjoner, som triamcinolon $10-40 \mathrm{mg} /$ $\mathrm{ml}$ i flere omganger. Hypotrofiske aknearr bør håndteres i rolig fase 12-24 måneder etter avsluttet aknebehandling. Alternativene er mange, men ikke alltid gode - dermabrasio, kjemisk peeling, kirurgiske inngrep og laserbehandling, bl.a. fraksjonert $\mathrm{CO}_{2}$-laser og YAG-laser (3). Slik behandling utføres av enkelte hudleger og plastikkirurger.

Postinflammatorisk hyperpigmentering ses særlig hos personer med mørk hudtype

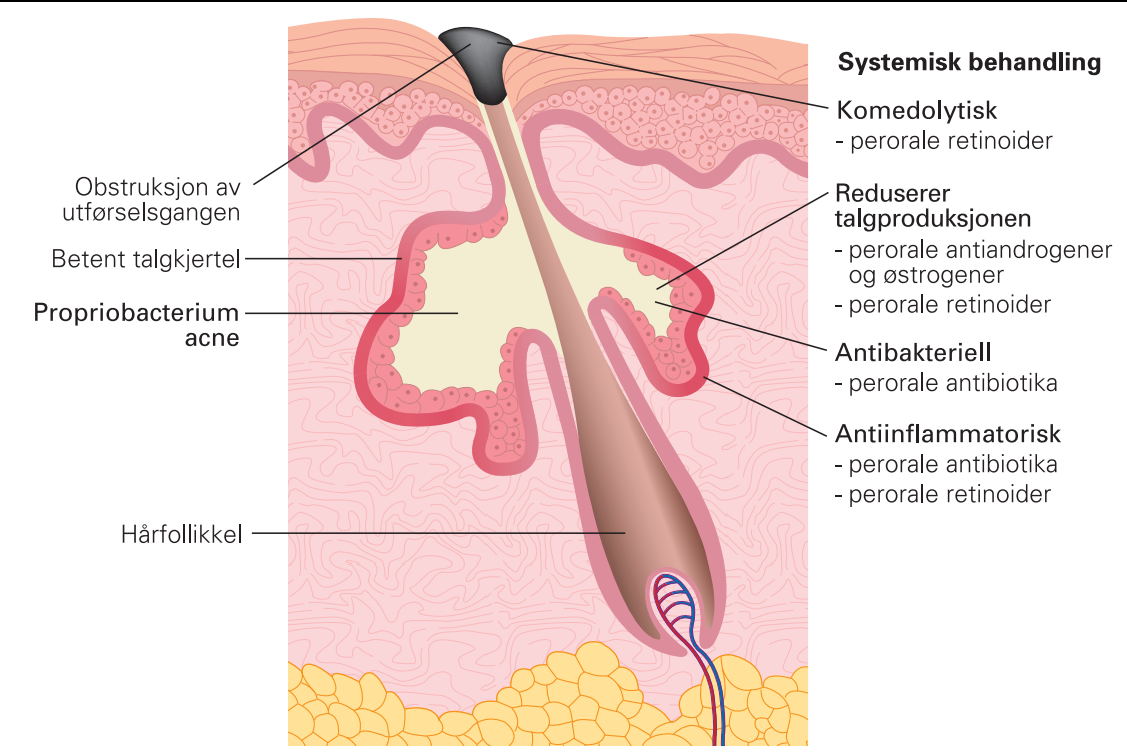

Figur 1 Talgkjertelens anatomi og angrepspunkter for ulike systemiske legemidler

og kan være til stede i opptil 18 måneder, men avtar så spontant.

\section{Konklusjon}

Moderat og alvorlig akne skal først og fremst behandles med systemiske antibiotika, slik som tetrasykliner, helst i kombinasjon med lokale keratolytiske og/eller antibakterielle midler. Pasienter med arrdannende eller alvorlig akne og de som har hatt manglende effekt av annen behandling, bør henvises hudlege med tanke på systemisk behandling med isotretinoin.

Oppgitte interessekonflikter: Ingen

\section{Litteratur}

1. Mikkelsen CS, Hansen SR, Kroon S. Lokalbehand ling av akne. Tidsskr Nor Legeforen 2010; 130: 33-4.

2. Kaymak Y, Taner E, Taner Y. Comparison of depression, anxiety and life quality in acne vulgaris patients who were treated with either isotretinoin or topical agents. Int J Dermatol 2009; 48: 41-6.

3. Gollnick H, Cunliffe W, Berson D et al; Global Alliance to Improve Outcomes in Acne. Management of acne: a report from a Global Alliance to Improve Outcomes in Acne. J Am Acad Dermatol 2003; 49 (suppl): S1-37.

4. Layton AM, Dreno B, Gollnick HP et al. A review of the European Directive for prescribing systemic isotretinoin for acne vulgaris. J Eur Acad Dermato Venereol 2006; 20: 773-6.

5. Thiboutot D, Gollnick H, Bettoli V et al; Global Alliance to Improve Outcomes in Acne. New insights into the management of acne: an update from the Global Alliance to Improve Outcomes in Acne group. J Am Acad Dermatol 2009; 60 (suppl): $\mathrm{S} 1-50$.

6. Dréno B, Bettoli V, Ochsendorf F et al; European Expert Group on Oral Antibiotics in Acne. European recommendations on the use of oral antibiotics for acne. Eur J Dermatol 2004; 14: 391 -9.

7. Goodfield MJ, Cox NH, Bowser A et al. Advice on the safe introduction and continued use of isotretinoin in the U.K. 2010. Br J Dermatol 2010; 162: 1172-9.

8. Brown J, Farquhar C, Lee 0 et al. Spironolactone versus placebo or in combination with steroids for hirsutism and/or acne. Cochrane Database Syst Rev 2009; nr. 2: CD000194

9. Hædersdal M, Togsverd-Bo K, Wulf HC. Evidencebased review of lasers, light sources and photodynamic therapy in the treatment of acne vulgaris. J Eur Acad Dermatol Venereol 2008: 22: 267-78.

10. Holland DB, Jeremy AH, Roberts SG et al. Inflammation in acne scarring: a comparison of the responses in lesions from patients prone and not prone to scar. Br J Dermatol 2004; 150: 72-81. 